\title{
8
}
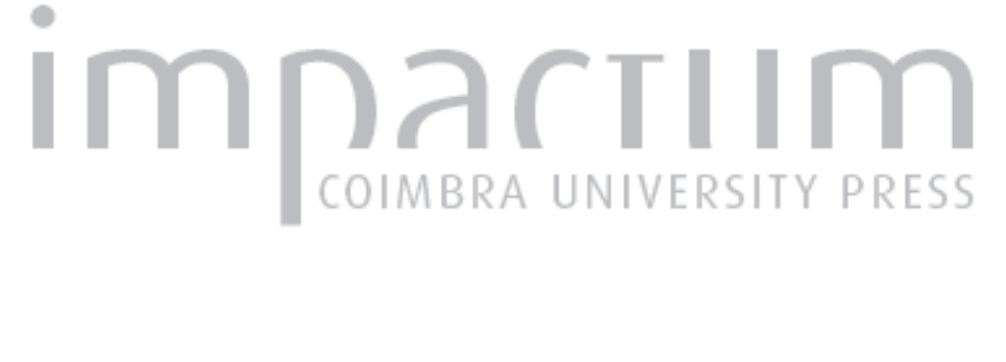

\section{A importância da imagem na afirmação do socorro: a experiência da força especial de bombeiros}

\author{
Autor(es): $\quad$ Caldeira, Pedro
}

Publicado por: Associação Portuguesa de Riscos, Prevenção e Segurança; Imprensa

URL

persistente:

da Universidade de Coimbra

DOI:

URI:http://hdl.handle.net/10316.2/39795

DOI:https://doi.org/10.14195/1647-7723_23_17

Accessed : $\quad$ 26-Apr-2023 08:53:13

A navegação consulta e descarregamento dos títulos inseridos nas Bibliotecas Digitais UC Digitalis, UC Pombalina e UC Impactum, pressupõem a aceitação plena e sem reservas dos Termos e Condições de Uso destas Bibliotecas Digitais, disponíveis em https://digitalis.uc.pt/pt-pt/termos.

Conforme exposto nos referidos Termos e Condições de Uso, o descarregamento de títulos de acesso restrito requer uma licença válida de autorização devendo o utilizador aceder ao(s) documento(s) a partir de um endereço de IP da instituição detentora da supramencionada licença.

Ao utilizador é apenas permitido o descarregamento para uso pessoal, pelo que o emprego do(s) título(s) descarregado(s) para outro fim, designadamente comercial, carece de autorização do respetivo autor ou editor da obra.

Na medida em que todas as obras da UC Digitalis se encontram protegidas pelo Código do Direito de Autor e Direitos Conexos e demais legislação aplicável, toda a cópia, parcial ou total, deste documento, nos casos em que é legalmente admitida, deverá conter ou fazer-se acompanhar por este aviso.

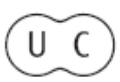




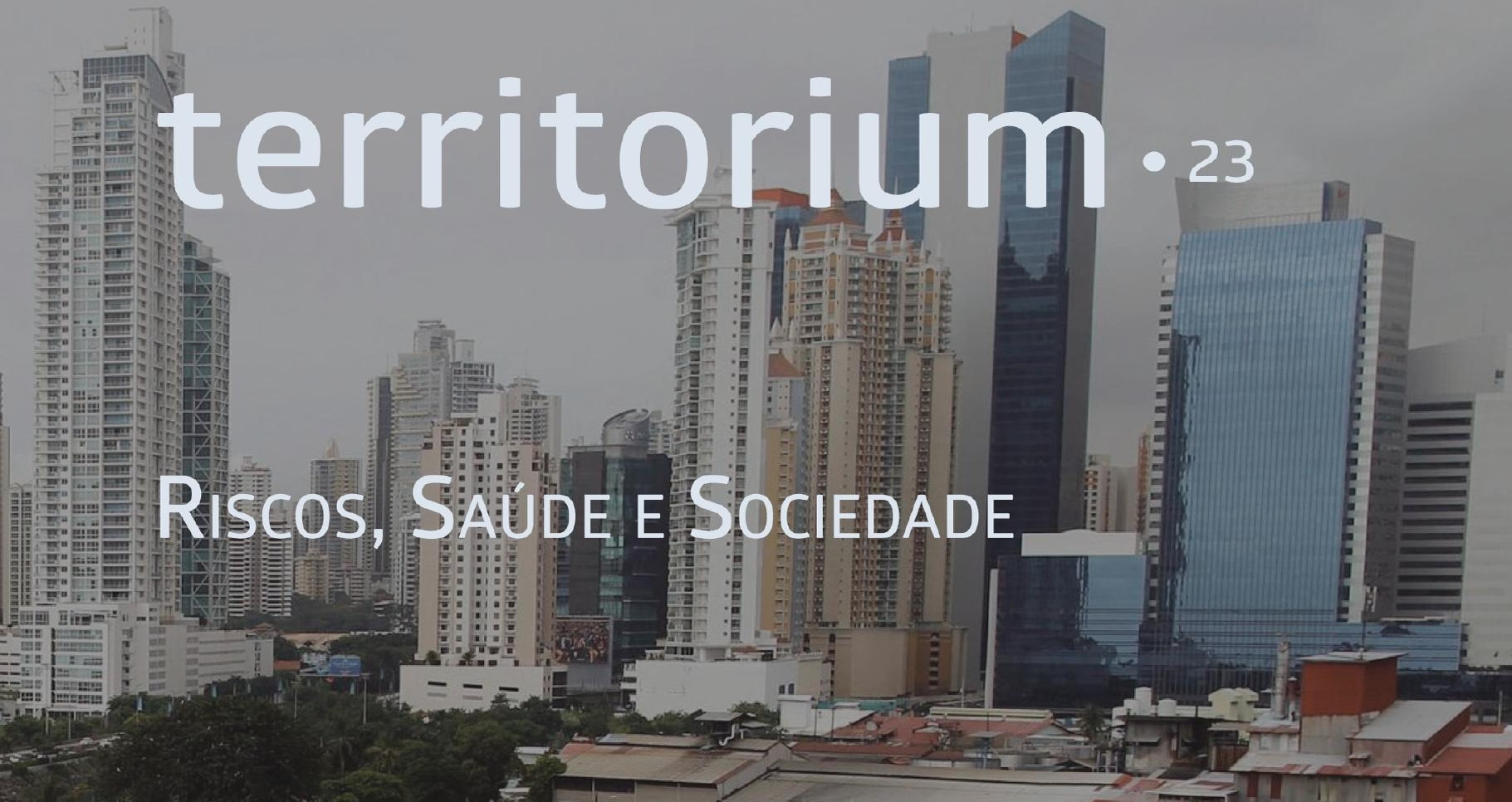

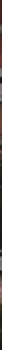

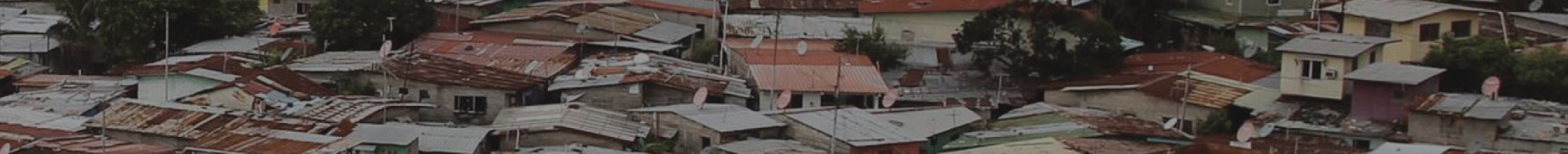

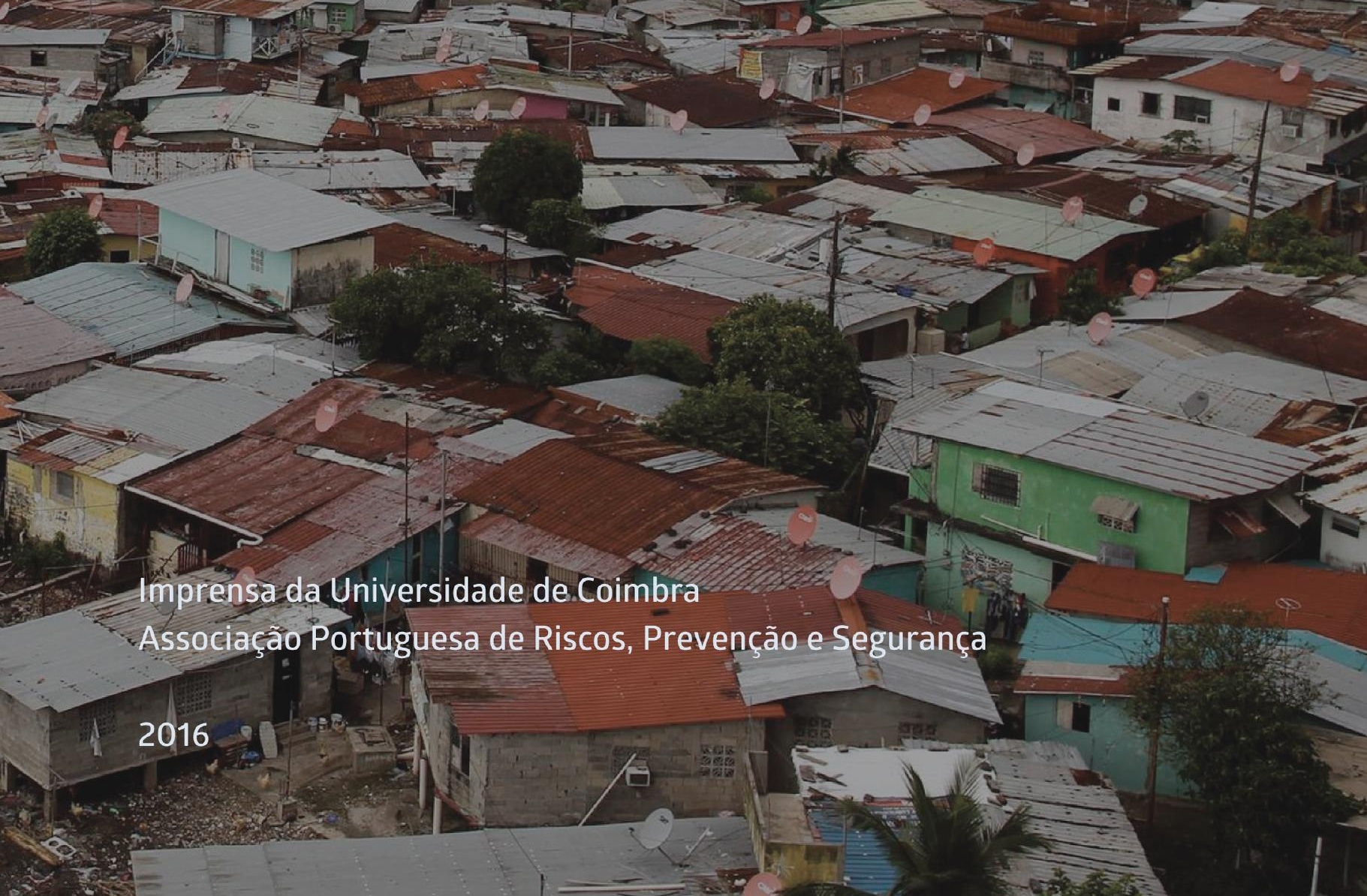




\section{A IMPORTÂNCIA DA IMAGEM NA AFIRMAÇÃO DO SOCORRO. A EXPERIÊNCIA DA FORÇA ESPECIAL DE BOMBEIROS*}

THE IMPORTANCE OF IMAGE IN RELIEF OF STATMENT. THE EXPERIENCE OF THE SPECIAL FORCE OF FIREFIGHTERS

Pedro Caldeira

Força Especial de Bombeiros - Autoridade Nacional de Proteção Civil - Portugal pedro.caldeira@prociv.pt

\section{RESUMO}

A Força Especial de Bombeiros é uma Força Especial de Proteção Civil, dotada de estrutura e comando próprio. Depende administrativa e operacionalmente da Autoridade Nacional de Proteção Civil. Dispõe de um quadro permanente de 270 operacionais e uma disposição territorial de nível nacional. Executa essencialmente a sua missão nas áreas do combate a incêndios florestais, salvamento aquático, resgate em montanha, busca e salvamento aéreo, salvamento em grande ângulo, apoio logístico, equipas de posto de comando de reserva nacional, análise e uso fogo e reconhecimento e avaliação da situação.

Palavras-chave: Bombeiros, Proteção Civil, incêndios florestais, imagem institucional.

\section{ABSTRACT}

The Special Force of Firefighters is a Special Forces Civil Protection, endowed with structure and command itself. Administrative and operationally dependent of the National Civil Protection Authority. It has a permanent staff of 270 operating and territorial provision of national level. Essentially performs its mission in the areas of fighting forest fires, water rescue, mountain rescue, search and air rescue, rescue in wide angle, logistical support, national reserve command post teams, analysis and use of fire and recognition and evaluation the situation.

Keywords: Firemen, Civil Protection, forest fires, institutional image.

Introdução

O projeto da Força Especial de Bombeiros (FEB) remonta ao ano de 2005, com a criação das então denominadas "Brigadas Helitransportadas" (fig. 1). 0 objetivo passou pela aplicação estratégica de operacionais, na forma de equipas ou brigadas, no combate a incêndios florestais nascentes.

Baseado no resultado satisfatório, determinou a tutela que se iniciasse a formação de uma Companhia Especial de Bombeiros, numa primeira fase em 2007, distribuída pelos distritos da Guarda, Castelo Branco, Santarém e Portalegre. No ano de 2008 foram criadas condições para a expansão da Força, desta vez contemplando um alargamento territorial aos distritos de Évora, Setúbal e

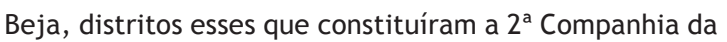
FEB. Paralelamente iniciou-se a preparação e qualificação dos operacionais para intervenções em ocorrências de outras naturezas. No ano de 2009 procedeu-se a uma reestruturação tática dos recursos existentes e foi criada uma terceira Companhia. Desde então e até aos

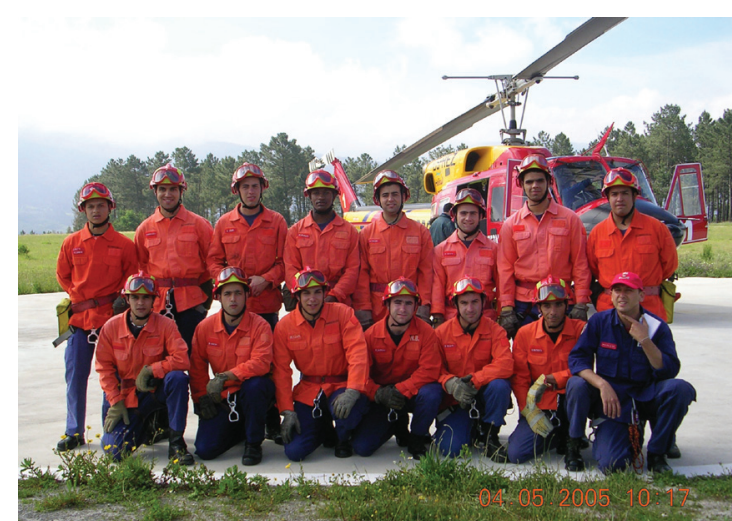

Fig. 1 - Curso de Brigadas Helitransportadas do ano de 2005. Escola Nacional de Bombeiros da Lousã (Fonte: Gabinete de Comando da Força Especial de Bombeiros).

Fig. 1 - Helicopter brigades course of 2005. National School of Firemen Lousã (Source: Command Office of Special Fire Force).

dias de hoje, a FEB é representada por um Batalhão a três Companhias. A $1^{\text {a }}$ Companhia compreende os distritos da Guarda e Castelo Branco, a $2^{\mathrm{a}}$ Companhia

* O texto desta nota foi submetida em 26-01-2016, sujeita a revisão por pares a 21-03-2016 e aceite para publicação em 30-06-2016. Esta nota é parte integrante da Revista Territorium, n. ${ }^{\circ} 23,2016,{ }^{\circ}$ RIscos, ISSN: 0872-8941. 
os distritos de Évora, Setúbal e Beja e a $3^{\text {a }}$ Companhia os distritos de Santarém e Portalegre, sem prejuízo da sua aplicação em qualquer ponto de território nacional ou internacional. $\mathrm{Na}$ sede da Autoridade Nacional de Proteção Civil (ANPC) em Carnaxide, encontrase sediado o Comando desta Força, coadjuvado por uma unidade de apoio que desenvolve a sua atividade essencialmente ao nível administrativo.

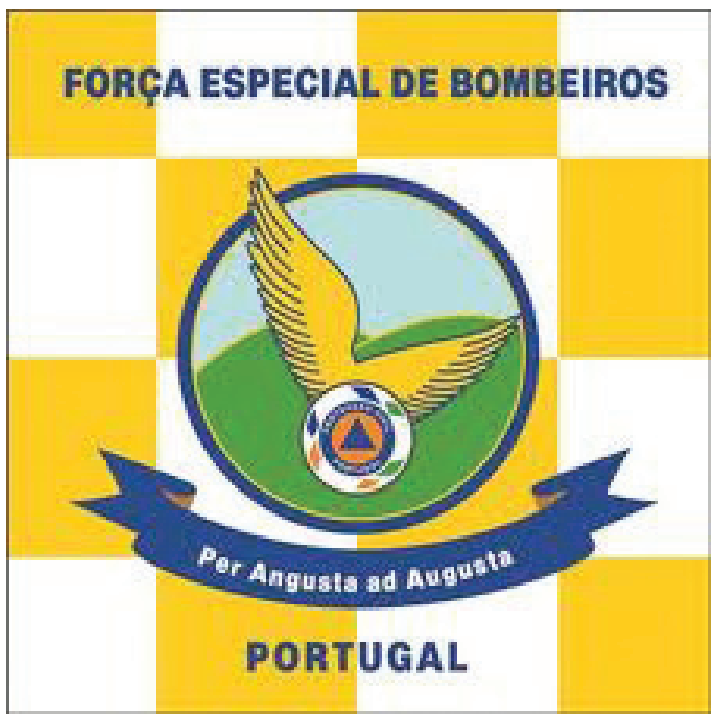

Fig. 2 - Guião da Força Especial de Bombeiros (Fonte: Gabinete de Comando da FEB).

Fig. 2 - Script of the Special Force of Firemen (Source: Command Office of Special Fire Force).

\section{Empenhamento}

No que concerne aos incêndios florestais o modo de empenhamento pode ter dois modelos, inseridos no Dispositivo Especial de Combate a Incêndios Florestais (DECIF) da ANPC, que prevê numa vertente helitransportada e um modelo de intervenção terrestre. A vertente helitransportada, normalmente desenvolvida nas fases Bravo, Charlie e Delta do Dispositivo Especial de Combate a Incêndios Florestais (DECIF), atribui à FEB a operacionalização de helicópteros ligeiros e médios de combate a incêndios florestais. Estas equipas, que operam a partir de locais previamente estipulados, têm como missão assegurar a primeira intervenção no combate, num raio de 40 quilómetros desde Centros de Meios Aéreos (CMA), sem prejuízo da mobilidade que the é reconhecida e empenhamento em qualquer ponto do território nacional. A fig. 3 demonstra a atividade destas equipas nos últimos três anos.

A intervenção terrestre teve duas fases distintas de empenhamento, na medida em que na fase Charlie dos

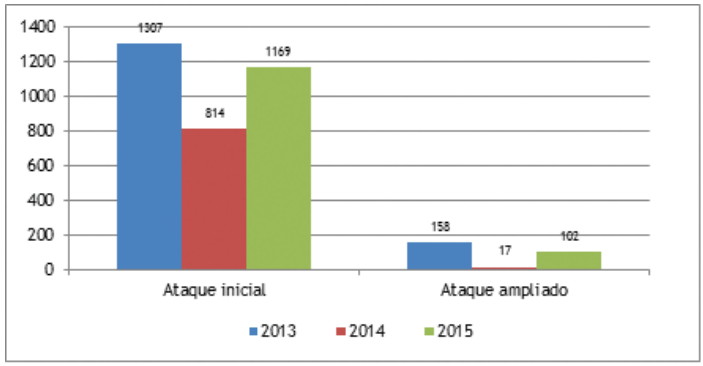

Fig. 3 - Total de intervenções helitransportadas nos anos de 2013, 2014 e 2015 (Fonte: ANPC).

Fig. 3 - Total helicopter interventions in the years 2013, 2014 and 2015 (Source: ANPC).

três últimos dispositivos (DECIF 2013¹, DECIF 2014 e DECIF 2015), por decisão do Comando Nacional de Operações de Socorro (CNOS), os meios terrestres permaneceram agrupados, 24 horas por dia, com um grau de prontidão de 15 minutos, sob a forma de Grupo de Ataque Ampliado (GRUATA), CNOS ANPC (2014, 2015).

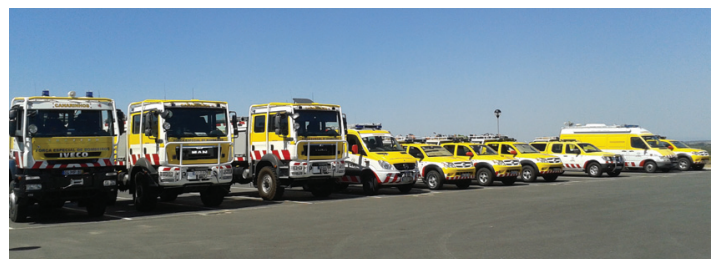

Fig. 4 - Grupo de Ataque Ampliado da FEB (Fonte: Gabinete de Comando da FEB).

Fig. 4 - FEB Expanded attack group (Source: Command Office of Special Fire Force).

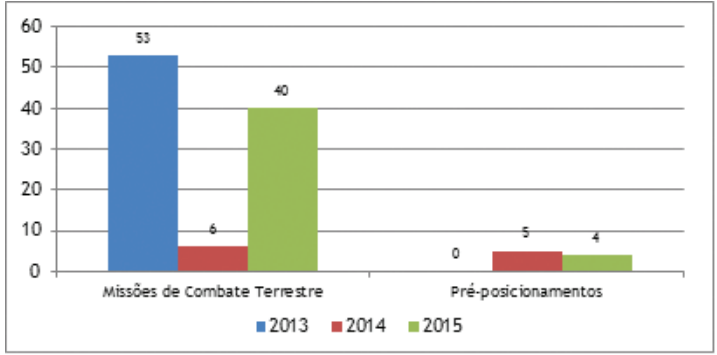

Fig. 5 - Relação de intervenções do GRUATA da FEB (Fonte: Gabinete de Comando da FEB).

Fig. 5 - Ratio of the Expanded Strike Group FEB's interventions (Source: Command Office of Special Fire Force).

Em relação a este modelo de intervenção (GRUATA), verifica-se um nível de resposta em tempo útil, associando o agrupamento permanente dos recursos ao grau de prontidão estipulado e ao seu comandamento próprio, traduzido no número e eficácia das intervenções.

${ }^{1}$ Durante a fase Charlie do DECIF 2013, o GRUATA da FEB assumiu a formatação de 12 horas diárias com um estado de prontidão de 15 minutos. 
Nas restantes fases do DECIF, os recursos terrestres operaram isoladamente a partir dos seus distritos de origem, sem prejuízo do seu agrupamento em caso de necessidade.

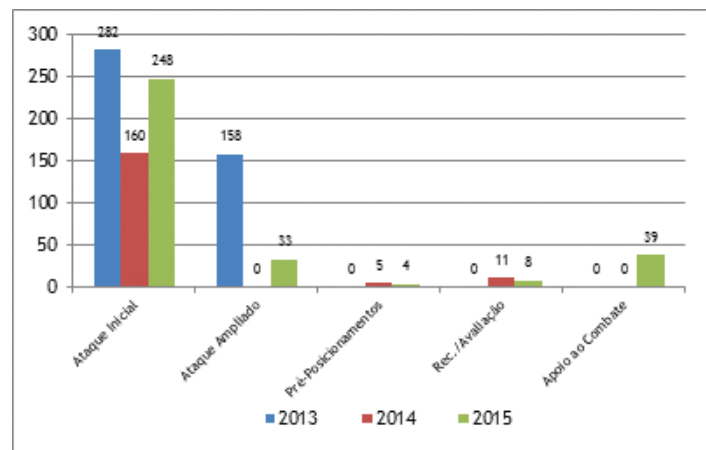

Fig. 6 - Relação de intervenções terrestres, a operar isoladamente a partir dos seus distritos de origem (Fonte: Gabinete de Comando FEB).

Fig. 6 - Ratio of land interventions to operate in isolation from their home districts

(Source: Command Office of Special Fire Force).

Ainda durante as fases Charlie dos últimos quatro anos, a FEB integra também o Dispositivo Conjunto da Defesa da Floresta Contra Incêndios - Parque Nacional Peneda Gerês (DCDFCl-PNPG), com o pré-posicionamento de uma equipa 24 horas por dia, a operar a partir da zona do Ramiscal, Adrão, no distrito de Viana do Castelo. Esta equipa desenvolve maioritariamente a sua missão dividida por patrulhamentos e monitorizações, numa forte componente dissuasora e relação de proximidade com as populações.

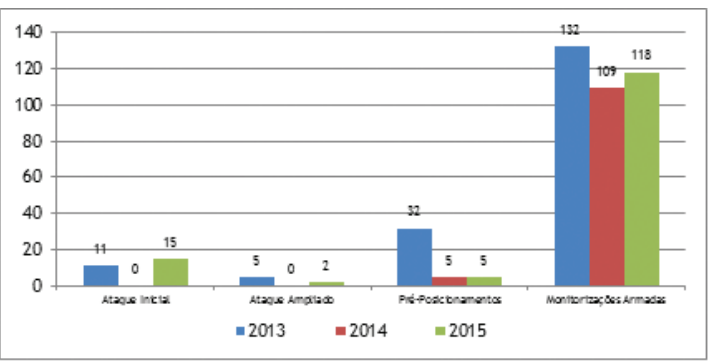

Fig. 7 - Relação de intervenções terrestres, inseridas no DCDFCI-PNPG (Fonte: Gabinete de Comando da FEB).

Fig. 7 - Ratio of land interventions, inserted in DCDFC-PNPG (Source: Command Office of Special Fire Force).

Através da $1^{\text {a }}$ Companhia, a FEB operacionaliza um conjunto de recursos direcionados à busca e resgate em ambiente de montanha. Normalmente integrados no Dispositivo Conjunto de Proteção e Socorro na Serra da Estrela no período de dezembro a abril, sem prejuízo da sua mobilização em qualquer espaço temporal, e em qualquer local do território nacional ou internacional, desenvolvem a sua atividade essencialmente na busca de pessoas desaparecidas, na assistência a veículos imobilizados em ambiente de montanha, com ou sem neve. A fig. 8 quantifica a atividade deste grupo, no âmbito do resgate em montanha.

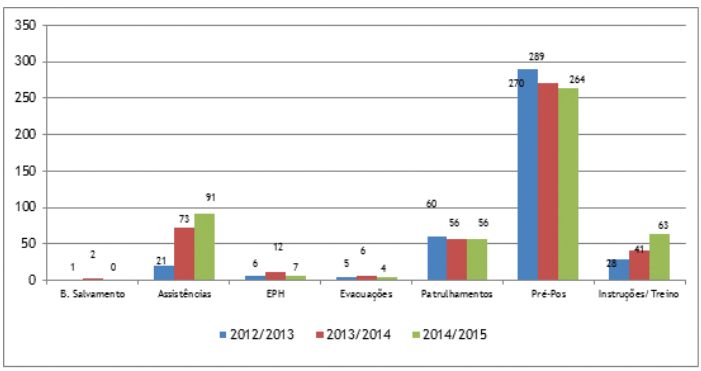

Fig. 8 - Atividade do Grupo de Resgate em Montanha (Fonte: Gabinete de Comando da FEB).

Fig. 8 - Mountain Rescue Group's Activity (Source: Command Office of Special Fire Force).
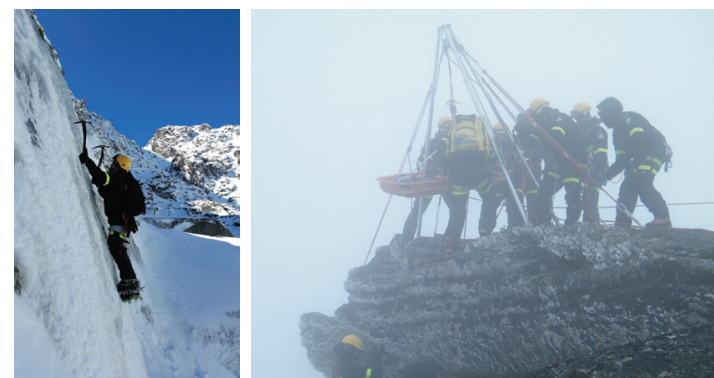

Figs. 9 e 10 - Missão de treino do Grupo de Resgate em Montanha (Fonte: Gabinete de Comando da FEB).

Fig. 9 and 10 - Mountain Rescue Group training mission (Source: Command Office of the Fire Department Special Force).

A FEB dispõe também de recursos que permitem operacionalizar um conjunto de atribuições na área do salvamento aquático, busca e salvamento aérea, apoio logístico, equipas de posto de comando de reserva nacional, reconhecimento e avaliação da situação, análise e uso do fogo e operadores de telecomunicações de emergência. $\mathrm{Na}$ área do socorro aquático, uma brigada garante esta atribuição, a partir dos distritos de Évora, Beja e Setúbal, com especial empenhamento na albufeira do Alqueva, sem prejuízo da sua mobilização para qualquer ponto do território nacional ou internacional.

A busca e salvamento aéreo são garantidos pela especialidade de Recuperador Salvador, em redundância à Força Aérea Portuguesa. Desenvolvem a sua atividade a partir das Bases de Helicópteros de Serviço Permanente (BHSP) localizadas em Loulé, distrito de Faro, e Santa comba Dão no distrito de Viseu, com especial incidência na busca e resgate de vítimas no mar e em terra, bem como no apoio a evacuações médicas por via aérea.

O apoio logístico representa uma área estratégica de âmbito nacional. A FEB dispõe de uma brigada que operacionaliza os recursos da ANPC, nomeadamente ao nível do apoio á gestão de equipamentos, montagem de postos de comando, campos de desalojados entre outros. 


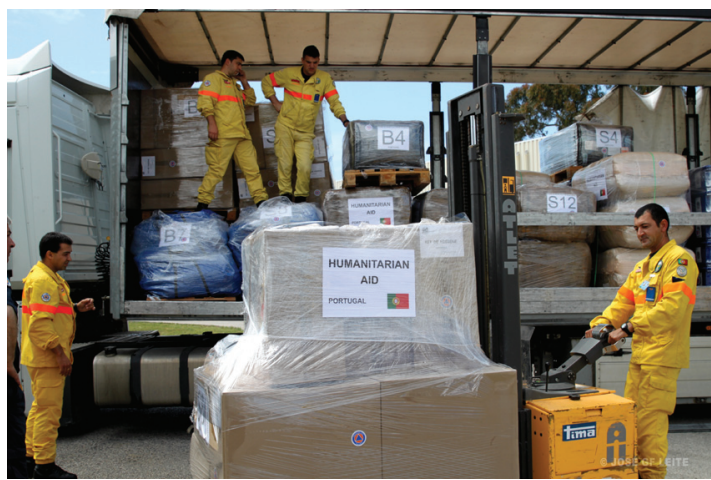

Fig. 11 - Preparação e envio de equipamento de assistência humanitária destinado à Bósnia e Sérvia, por ocasião de inundações (Fonte: Gabinete de Comando da FEB).

Fig. 11 - Preparation and delivery of humanitarian assistance equipment for Bosnia and Serbia (Source: Command Office of Special Fire Force).

Os elementos de Comando e Chefia superior constituem também equipas de posto de comando operacional de reserva nacional, mobilizados à ordem do CNOS da ANPC.

No que concerne ao reconhecimento e avaliação da situação, a FEB dispõe de dois veículos exclusivos a esta atividade, afetos à $2^{\mathrm{a}}$ e $3^{\mathrm{a}}$ Companhias. Ambos os veículos dispõem de equipamentos técnicos de avaliação de ocorrências e apoio à decisão, sistemas de informação geográfica e de transmissão de informação. Esta atribuição permite apoiar o Comandante das Operações de Socorro (COS), os Comandos Distritais de Operações de Socorro (CDOS) e o CNOS.

$\mathrm{Na}$ área da análise e uso do fogo, a FEB conta com dois técnicos de fogo controlado e 12 técnicos de supressão nos seus quadros. Durante a fase Charlie do DECIF 2014, integraram as equipas de análise e uso do fogo, sob a coordenação técnica do Instituto de Conservação da Natureza e das Florestas (ICNF).

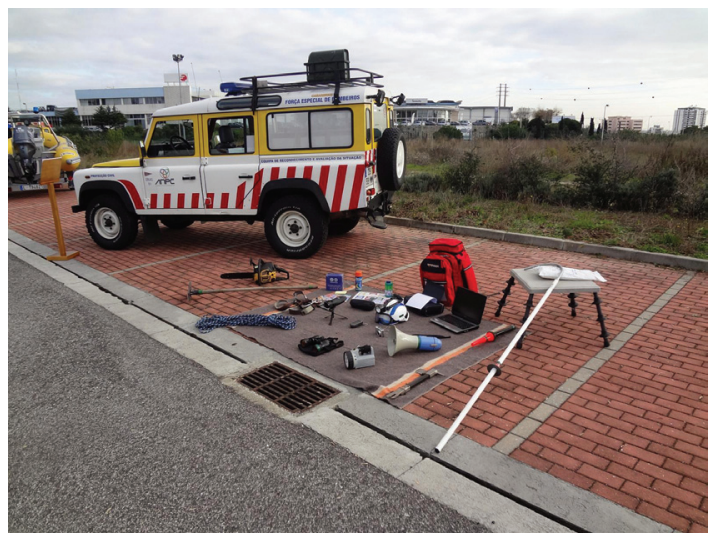

Fig. 12 - Veículo de reconhecimento e avaliação da situação (Fonte: Gabinete de Comando da FEB).

Fig. 12 - Reconnaissance vehicle and assessment of the situation (Source: Command Office of Special Fire Force).
A atribuição de telecomunicações de emergência permite operacionalizar o Veículo de Comando, Controlo e Comunicações, que integra o Centro Tático de Comando da ANPC, e permite também prestar apoio especializado aos Postos de Comando nos teatros de operações, aos CDOS e ao CNOS.

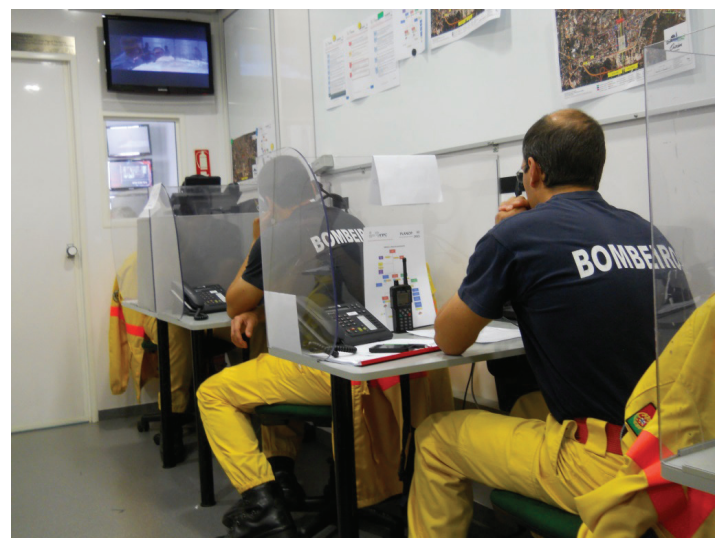

Fig. 13 - Veículo de Comando, Controlo e Comunicações da ANPC (Fonte: Gabinete de Comando da FEB).

Fig. 13 - Command vehicle, Control and Communications ANPC (Source: Command Office of Special Fire Force.)

Em termos de atividade fora de Portugal continental, foram surgindo algumas oportunidades da FEB participar em ações operacionais, de formação e treino, que em muito contribuíram não só para o enriquecimento individual e coletivo, mas também na área motivacional, Reis e Silva (2014). Na componente operacional destacam-se as intervenções no Haiti, em 2010, devido ao sismo que assolou a região. Na Região Autónoma da Madeira em duas ocasiões, a primeira em 2010 devido ao temporal e em 2012 no combate a incêndios florestais, e em Espanha, em 2015, também no combate a incêndios florestais. Nas ações de formação, na transmissão de conhecimentos a agentes de proteção civil em São Tomé e Príncipe, Moçambique e Guiné-Bissau. Por fim a participação em exercícios em Itália e França.

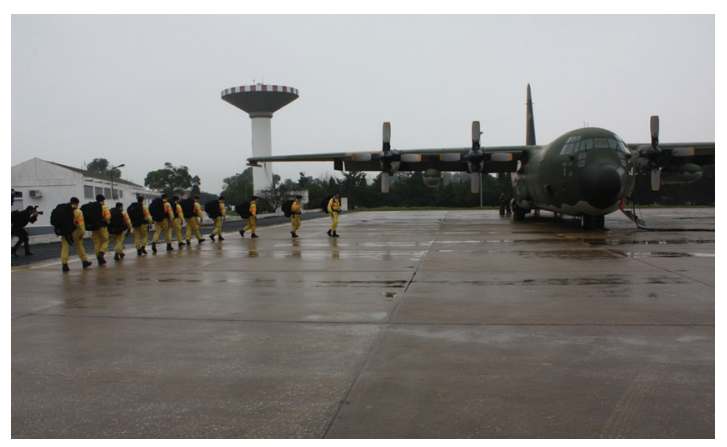

Fig. 14 - Embarque da Brigada da FEB para o Haiti. Aeroporto militar de Figo Maduro (Fonte: Gabinete de Comando da FEB).

Fig. 14 - Brigade shipment to Haiti (Source: Command Office of Special Fire Force). 


\section{A construção da imagem}

Abordando a questão da imagem, uma das mensagens chave fundamentais é que a FEB, apesar de dispor de recursos que permitem autonomia própria, é parte integrante da estrutura operacional da ANPC, estando vinculada à sua identidade corporativa. Comunica oficialmente através dos seus meios de comunicação habituais, utiliza novas tecnologias como o facebook, twitter, youtube, entre outros, com intervenção aos demais níveis da Divisão de Comunicação e Sensibilização da ANPC, Santos (2012). Não utiliza outras ferramentas de comunicação institucional ou outros terminais que não os oficiais.

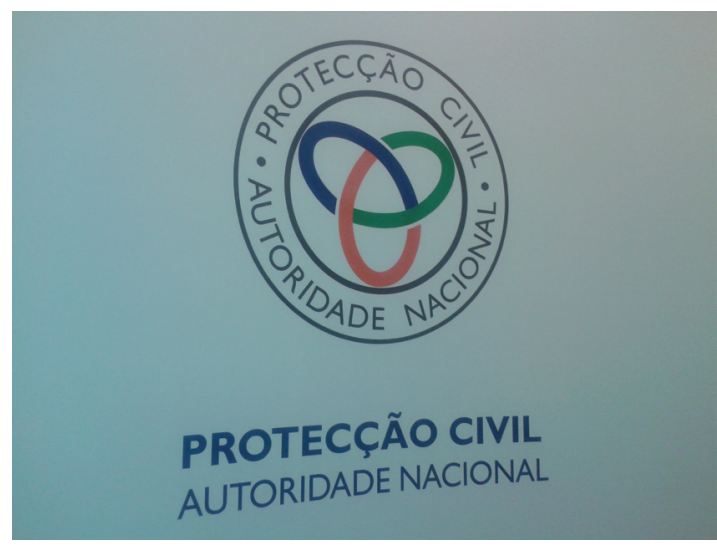

Fig. 15 - Simbologia institucional da ANPC (Fonte: Gabinete de Comando da FEB).

Fig. 15 - Institutional symbolism of ANPC (Source: Command Office of Special Fire Force).

Outra das ferramentas principais na construção da imagem é o universo de recrutamento da FEB, os corpos de bombeiros. A cultura nacional ${ }^{2}$, Reis e Silva (2014), deste universo de recrutamento representa uma mais-valia garantida das bases que satisfazem o perfil pretendido para os recursos humanos da FEB, o de bombeiro voluntário. O candidato tem de ser detentor da categoria mínima de bombeiro de $3^{\mathrm{a}}$, com idades compreendidas entre os 21 e 35 anos (três anos de experiência), e com escolaridade mínima ao nível do $12^{\circ}$ ano ou equivalente. É também valorizada a força individual de trabalho (capacidade de execução de tarefas físicas e intelectuais), Reis e Silva (2014), quer seja na avaliação curricular quer em cursos de aperfeiçoamento técnico e de progressão na carreira que o candidato seja detentor.

0 processo de recrutamento contempla três momentos, a formação inicial, o treino operacional e a integração no serviço da FEB. Selecionados os candidatos, é

${ }^{2}$ Conjunto de valores coletivos fundamentais, que guiam a vida de um grupo humano situado num determinado espaço geográfico, o seu relacionamento com o meio ambiente, a sua interiorização, apresentando uma consubstanciação institucional. ministrada uma formação especializada na área do combate a incêndios florestais na Escola Nacional de Bombeiros da Lousã. Findo este primeiro período e não menosprezando as questões técnicas relacionadas com a formação inicial, inicia-se um treino operacional, da responsabilidade da FEB, que estimula o desenvolvimento individual e coletivo com o objetivo de integração, Reis e Silva (2014), no qual é desenvolvido um forte incremento no rigor e disciplina, apresentação, enquadramento de comportamentos (como exemplo a proibição de consumo de bebidas alcoólicas quando fardados), a promoção do espírito de corpo e de grupo, e no cumprimento escrupuloso das normas e diretrizes que julgamos fundamentais à boa imagem individual e coletiva da FEB. Por fim, são afetados os finalistas aos grupos de trabalho e procede-se ao seu acolhimento, socialização, Reis e Silva (2014) e integração no serviço da FEB.

Uma das ferramentas que julgamos importante na construção da imagem é a dotação de todo o efetivo com o mesmo vestuário e demais equipamento individual, por forma a impossibilitar as diferenças. Outro contributo essencial na construção da imagem individual e coletiva são as ações diárias internas, como formação e treino nas áreas de ação da Força, quer seja nos incêndios florestais, quer na ordem unida, entre outras, com efeitos no processo anual de avaliação de desempenho.

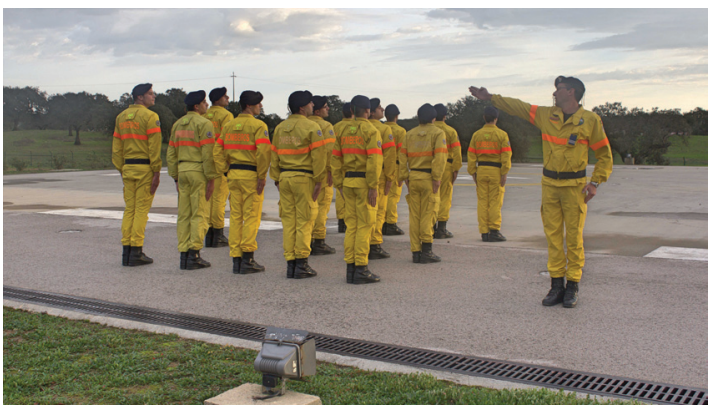

Fig. 16 - Treino diário de ordem unida (Fonte: Gabinete de Comando da FEB).

Fig. 16 - Daily workout united order (Source: Command Office of Special Fire Force).

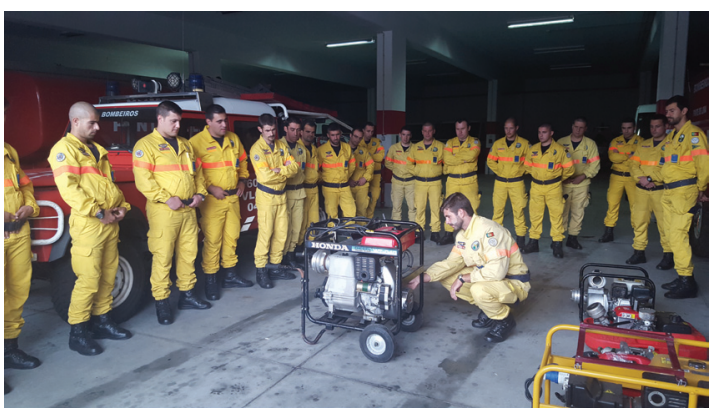

Fig. 17 - Instrução de motobombas (Fonte: Gabinete de Comando da FEB).

Fig. 17 - Instructions for motor pumps (Source: Command Office of Special Fire Force). 
Parte do valor final da avaliação anual de desempenho é ponderada entre variáveis, funcionais e de responsabilidades, Reis e Silva (2014), entre as quais a imagem individual, que é aferida na avaliação diária nos grupos. Nesta avaliação qualitativa são ponderados a uniformidade, o brio e limpeza do fardamento, o estado do cabelo, da barba, do vestuário e do calçado.

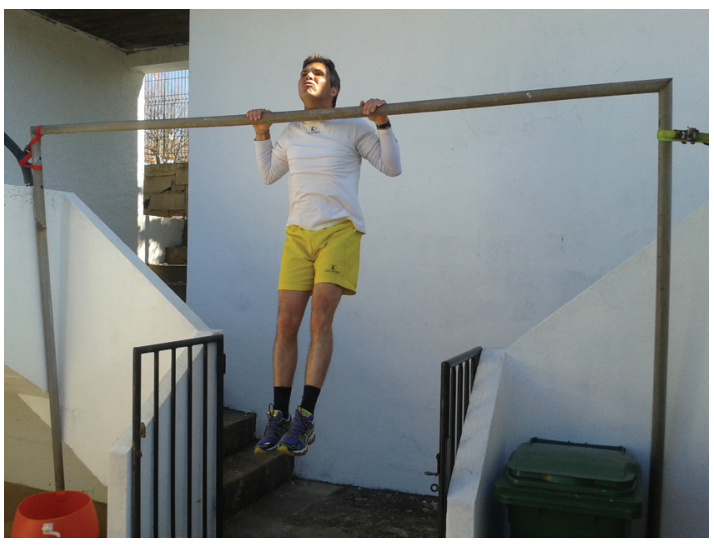

Fig. 18 - Elevações de braços na trave. Provas de aptidão física 2015 (Fonte: Gabinete de Comando da FEB).

Fig. 18 - Arm lift in the beam (Source: Command Office of Special Fire Force).

Por fim, genericamente, existem outros instrumentos que contribuem ativamente para a construção e manutenção da imagem e uniformização de procedimentos, como as ordens de operações (destinadas a ações específicas, limitadas no tempo e no espaço), e os comunicados técnico-operacionais da FEB (normalmente associados a medidas extraordinárias, relacionadas com condições meteorológicas adversas), o Regulamento de Utilização de Veículos, que prevê os demais procedimentos do utilizador em relação à frota de veículos da ANPC. Em alguns momentos também são desenvolvidos treinos operacionais internos, especializados, com o apoio das várias Direções de Serviços da ANPC.

Outras oportunidades de construção e consolidação de imagem foram surgindo, com especial incidência para a interação com outros agentes de proteção civil, através de ações de formação e treino operacionais conjuntos, intervenções operacionais e à colaboração com a Escola Nacional de Bombeiros, na realização de formação nas áreas dos incêndios florestais, emergência pré-hospitalar, matérias perigosas, condução de veículos, salvamento em grande ângulo, telecomunicações e escoramentos. A FEB dispõe atualmente de 58 formadores nos seus quadros, acreditados para as diversas áreas formativas. Para a interação com o público exterior ao setor da proteção civil e bombeiros, através de ações de formação e sensibilização destinadas ao público em geral, pela participação nos demais dispositivos nacionais, para o cumprimento integral das regras relativamente à forma de estar nestas circunstâncias, e através das experiencia individual e coletiva recolhida pelos operacionais que constituem a Força.

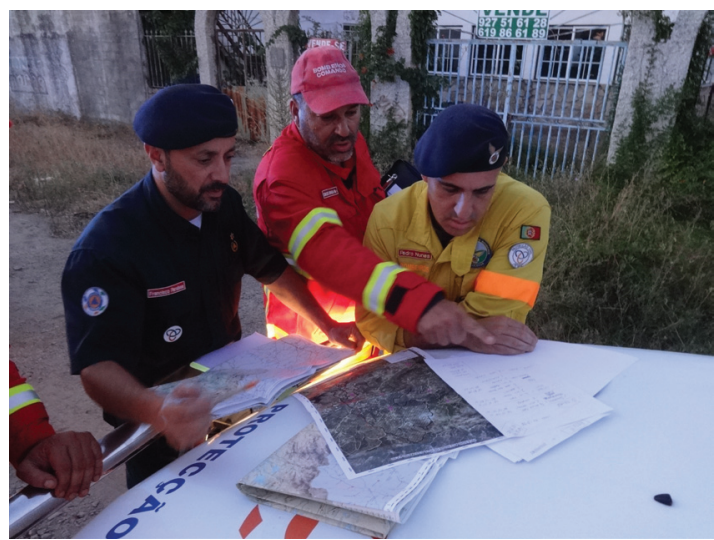

Fig. 19 - Planeamento de intervenção operacional. Incêndio florestal na Serra da Gata em Espanha, 2015 (Fonte: CNOS da ANPC).

Fig. 19 - Forest fire-fighting planning in Sierra de Gata in Spain, 2015 (Source: Command Office of Special Fire Force).

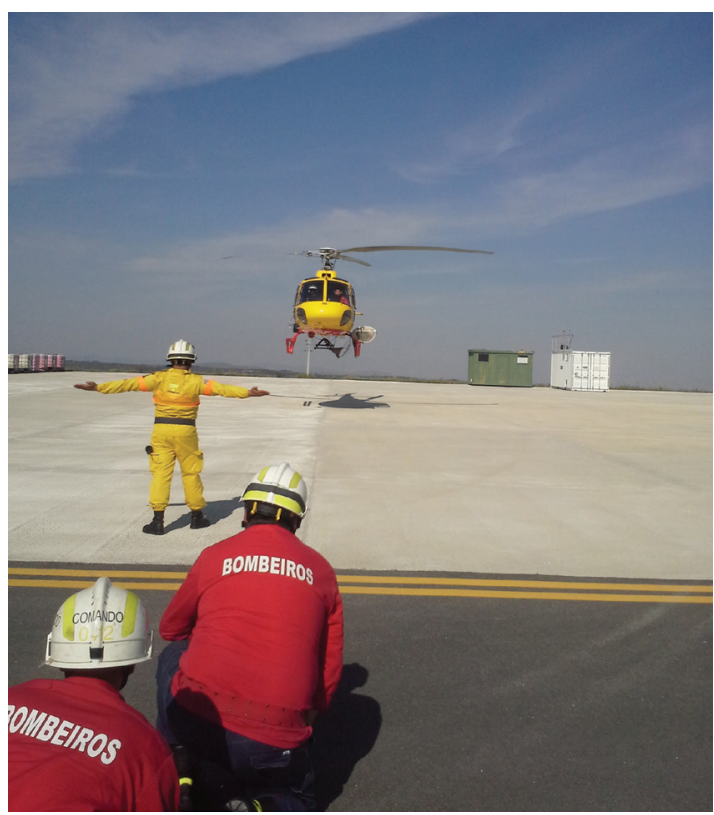

Fig. 20 - Curso de Operações aéreas de nível 1. Base de Apoio Logístico de Castelo Branco (Fonte: Gabinete de Comando da FEB).

Fig. 20 - Air operations level 1 course. Support Logistics Base Castelo Branco (Source: Command Office of Special Fire Force).

\section{Responsabilidade Social}

O setor da proteção civil representa uma área paradigmática, em constante mudança, e que à semelhança de muitos outros setores atuais de interação com o público em geral, representa um modelo que se 
pretende de referência na sociedade portuguesa. Englobados neste paradigma estão os bombeiros, eficientemente reconhecidos pela sociedade civil (GFK, 2014).

O estímulo da confiança do cidadão nas instituições deve ser ininterruptamente reforçado, e o seu objeto social esclarecido e operacionalizado ao nível das necessidades e do que é esperado por parte das instituições. À semelhança do paradigma do setor em Portugal, também o conceito de responsabilidade social deve ser considerado e visto numa perspetiva multidimensional, com o amplo contributo de todos os intervenientes incluindo a sociedade.

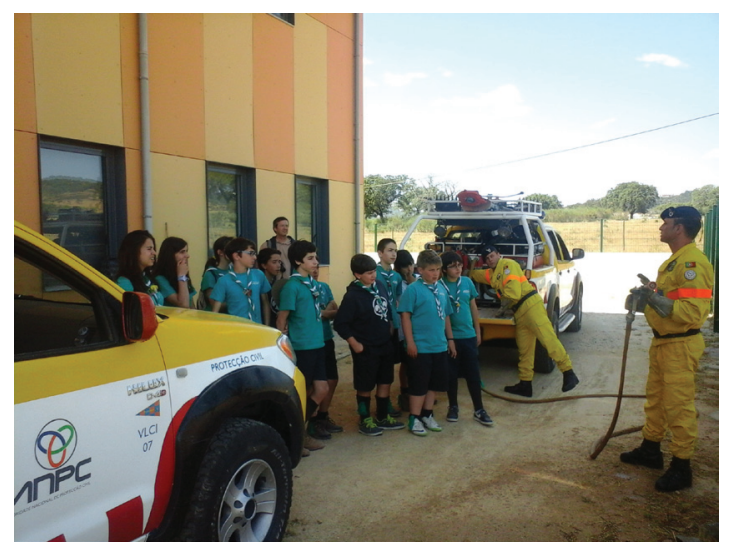

Fig. 21 - Ação de Sensibilização. Base Permanente de Portalegre. Fonte: Gabinete de Comando da FEB.

Fig. 21 - Awareness action (Source: Command Office of Special Fire Force).

\section{Caraterização do efetivo da FEB}

A FEB compreende um efetivo de 270 operacionais, oriundos de todo o território de Portugal continental, com a seguinte distribuição: Sete elementos no quadro de Comando; 90 elementos afetos à $1^{\text {a }}$ Companhia; 84 elementos afetos à $2^{\text {a }}$ Companhia; 74 elementos afetos à $3^{\text {a }}$ Companhia; 12 elementos no grupo de recuperadores salvadores; e dois elementos na Unidade de Apoio ao Comando.

Quanto à distribuição por sexo, verifica-se que $97 \%$ do efetivo da FEB é do sexo masculino e $3 \%$ do sexo feminino, conforme a fig. 22.

A média de idades situa-se nos 34,7 anos. Relativamente à distribuição, 71\% dos operacionais situam-se abaixo dos 35 anos, com o maior número de elementos na faixa etária dos 32 anos de idade.

De acordo com fig. 23, distribuição por habilitações literárias, $30 \%$ do efetivo tem o $9^{\circ}$ ano de escolaridade, $62 \%$ o $12^{\circ}, 7 \%$ de licenciados e $1 \%$ mestrados.

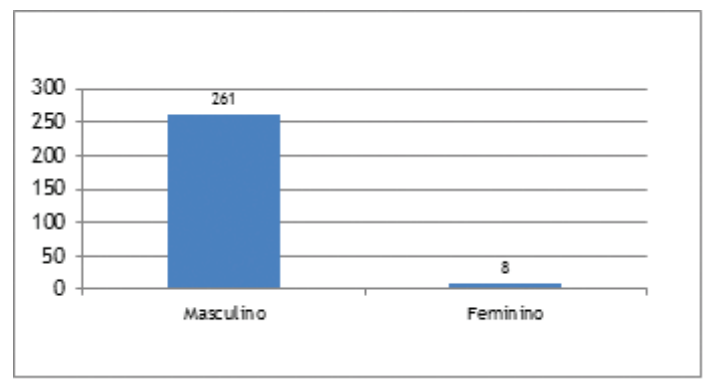

Fig. 22 - Distribuição do efetivo por sexo (Fonte: Gabinete de Comando da FEB).

Fig. 22 - Distribution by gender (Source: Command Office of Special Fire Force).

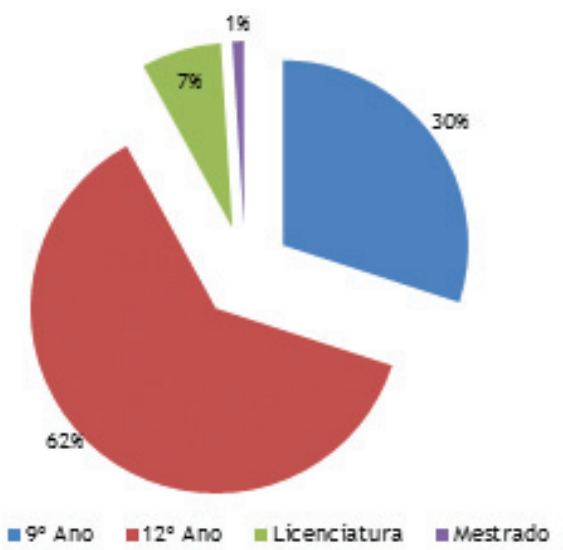

Fig. 23 - Distribuição do efetivo por habilitações literárias (Fonte: Gabinete de Comando da FEB).

Fig. 23 - Distribution by qualifications (Source: Command Office of Special Fire Force).

\section{Conclusão}

Genericamente a imagem da FEB foi construída ao longo da sua breve história, através das oportunidades que foram criadas não diretamente para o efeito, mas que contribuíram e contribuem decisivamente para a construção e manutenção da imagem. Em todo o sistema técnico da organização ${ }^{3}$, Reis e Silva (2014) não se identificam com a máxima de falem bem ou falem mal, o importante é falarem, mas sim no trabalho diário individual e coletivo que cada equipa desenvolve, não só ao nível das missões que lhes são atribuídas, mas também no brio e competência que cada elemento empenha no seu compromisso com o serviço da FEB, desde que prepara o seu uniforme e equipamento até ao momento em que termina uma missão, por muito rotineira que seja.

\footnotetext{
${ }^{3}$ Todos os meios utilizados para prestar um serviço.
} 
Consideramos também que o forte incremento no rigor e uniformização de procedimentos individuais e coletivos fundamentais na vida da organização, não só a formação inicial mas também nas missões diárias, proporcionam o efeito de unidade e cultura organizacional pretendidos, Reis e Silva (2014). Atividades preparatórias básicas como o tratamento regular do calçado e conservação do vestuário, a manutenção do cabelo no caso das mulheres e homens e da barba no caso dos homens, a cobertura da cabeça em locais a céu aberto, e a adequação comportamental ao cenário envolvente representam uma tarefa constante no processo evolutivo da Força.

Não obstante do que consideramos serem tarefas individuais e coletivas, algumas até do foro pessoal, a elaboração de ordens de operações, comunicados técnico-operacionais e outros documentos destinados a referenciar as ações a desenvolver, representam ferramentas indispensáveis na gestão e controlo de todos os objetivos a que a FEB se propõe.

A relação com as novas tecnologias de informação e comunicação representam também uma área sensível, essencial, que deve ser explorada e utilizada institucionalmente, cumprindo a política de imagem corporativa e tratamento de informação de cada entidade, Santos (2012).

\section{Bibliografia}

AUTORIDADE NACIONAL DE PROTEÇÃO CIVIL (2010) - Diretiva Operacional Nacional n. ${ }^{\circ} 1$ - Dispositivo Integrado de Operações de Proteção e Socorro.

AUTORIDADE NACIONAL DE PROTEÇÃO CIVIL (2015) Diretiva Operacional Nacional $n .{ }^{\circ} 2$ - Dispositivo Especial de Combate a Incêndios.

AUTORIDADE NACIONAL DE PROTEÇÃO CIVIL (2010) - Plano de Operações Nacional $n .^{\circ} 2$ - Dispositivo Conjunto de Defesa da Floresta Contra Incêndios no Parque Nacional da Peneda-Geres.

AUTORIDADE NACIONAL DE PROTECÃO CIVIL (2015) - Plano de Operações Nacional n. ${ }^{\circ} 4 / 2015$ - Dispositivo Conjunto de Proteção e Socorro na Serra da Estrela.

AUTORIDADE NACIONAL DE PROTECÃO CIVIL - GABINETE DE COMANDO DAFORÇA ESPECIAL DE BOMBEIROS (2012). Relatório de atividades da Força Especial de Bombeiros, 2012.

AUTORIDADE NACIONAL DE PROTECÃO CIVIL - GABINETE DE COMANDO DA FORÇA ESPECIAL DE BOMBEIROS (2013). Relatório de atividades da Força Especial de Bombeiros, 2013.

AUTORIDADE NACIONAL DE PROTEÇÃO CIVIL - GABINETE DE COMANDO DAFORÇA ESPECIAL DE BOMBEIROS (2014). Relatório de atividades da Força Especial de Bombeiros, 2014.
DESPACHO DO SECRETÁRIO DE ESTADO DA PROTEÇÃO CIVIL $n .{ }^{\circ} 22$ 396/2007, publicado em Diário da República, $2^{a}$ série, n. ${ }^{\circ} 186$, de 26 de Setembro de 2007, que cria a Força Especial de Bombeiros Canarinhos, ao abrigo do artigo $19^{\circ}$, do Decreto-Lei n. ${ }^{\circ}$ $247 / 2007$, de 27 de Junho, que aprovou o regime jurídico aplicável à constituição, organização, funcionamento e extinção dos corpos de bombeiros, no território continental. Revogado pelo Despacho do Secretário de Estado da Proteção Civil n. ${ }^{\circ} 14$ 456/2009, publicado no Diário da República, $2^{\mathrm{a}}$ série, $n$. $^{\circ}$ 123, de 29 de Junho de 2009.

DESPACHO DO PRESIDENTE DAAUTORIDADE NACIONAL DE PROTEÇÃO CIVIL n. ${ }^{\circ} 19$ 734/2009, publicado no Diário da República, $2^{\mathrm{a}}$ série, n. ${ }^{\circ} 167$, de 28 de Agosto de 2009 , que define a organização e funcionamento da Força Especial de Bombeiros Canarinhos.

DESPACHO DO DIRETOR NACIONAL DE BOMBEIROS DAAUTORIDADE NACIONAL DE PROTEÇÃO CIVIL n. ${ }^{\circ} 4 / 2009$, que organiza o funcionamento do Grupo de Recuperadores-Salvadores da Força Especial de Bombeiros.

DESPACHO DO PRESIDENTE DA AUTORIDADE NACIONAL DE PROTEÇÃO CIVIL n. ${ }^{\circ} 41 / 2010$, de 1 de Maio, que organiza o funcionamento do Grupo de Resgate em Montanha da Força Especial de Bombeiros.

DESPACHO DO PRESIDENTE DA AUTORIDADE NACIONAL DE PROTEÇÃO CIVIL n. ${ }^{\circ} 116 / 2010$, de 20 de Dezembro, que organiza o funcionamento do Grupo de Resposta Internacional da Força Especial de Bombeiros.

DESPACHO DO DIRETOR NACIONAL DE RECURSOS DE PROTEÇÃO CIVIL DA AUTORIDADE NACIONAL DE PROTEÇÃO CIVIl, de 17 de Março de 2011, que constitui a Unidade de Apoio Administrativo e Logístico ao Comando da Força Especial de Bombeiros.

DESPACHO DO PRESIDENTE DA AUTORIDADE NACIONAL DE PROTEÇÃO CIVIL n. ${ }^{\circ}$ 32-P/2011, de 18 de Março, que organiza o funcionamento da Brigada de Apoio Logístico da Força Especial de Bombeiros.

GFK (2014, Maio, 13) - Estudo global sobre a credibilidade em determinadas profissões. GFK Press Releases, on line, disponível em http://www.gfk. com/br/news-and-events/press-room/pressreleases/Paginas/ESTUDO-GLOBAL-SOBRE-ACREDIBILIDADE-EM-DETERMINADAS-PROFISSOES- . aspx, consultado em 25 de Novembro de 2015.

Silva, V. P. e Reis, Felipa (2014). Capital Humano - Temas para uma boa gestão das organizações, Lisboa, Edições Sílabo.

Santos, Carla Sofia da Silva (2012). Gabinetes de comunicação online como o novo caminho da comunicação externa das empresas (Dissertação de Mestrado em Ciências da Comunicação. Especialização em Comunicação Estratégica). Faculdade de Ciências Sociais e Humanas, Universidade Nova de Lisboa, Lisboa, 117; Disponível em http:// run.unl.pt/bitstream/10362/7398/2/ Disserta\%C 3\% A 7\%C 3\%A30\%20Carla\%20 Santos\%20n\%C2\%BA30587.pdf, consultado em 24 de Novembro de 2015. 

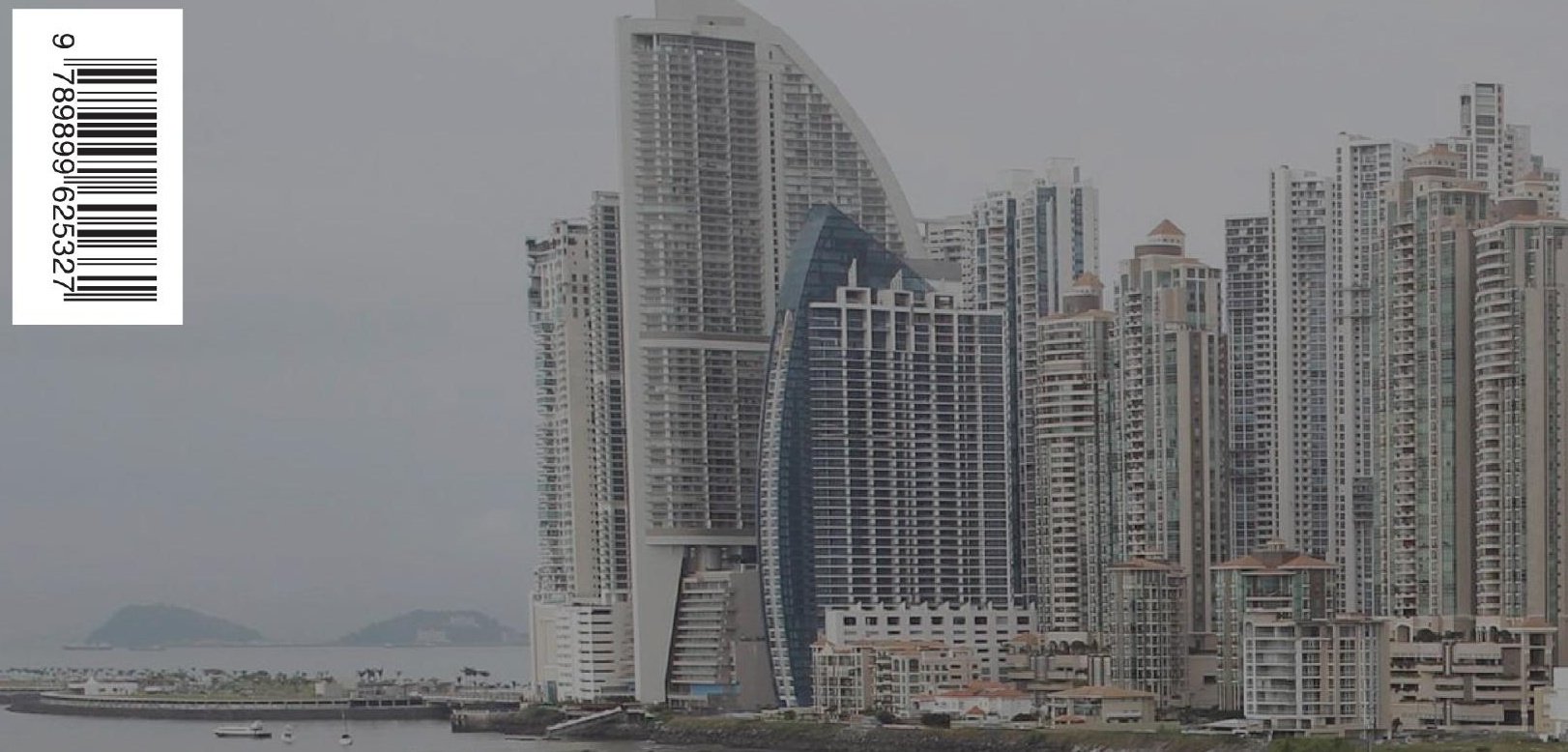

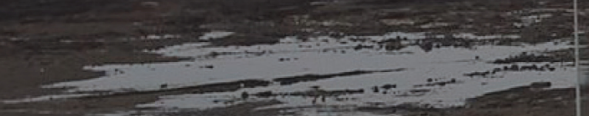

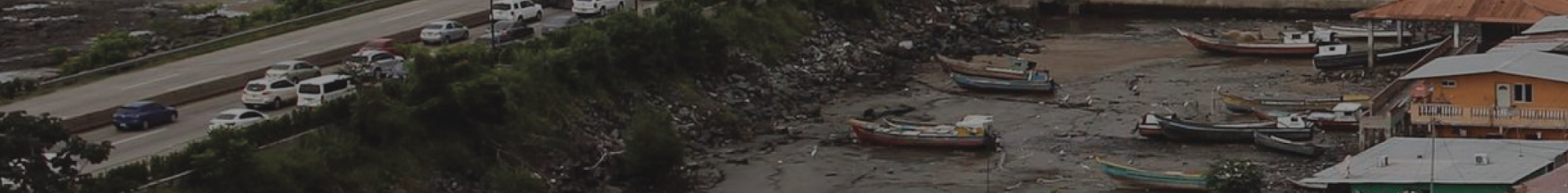

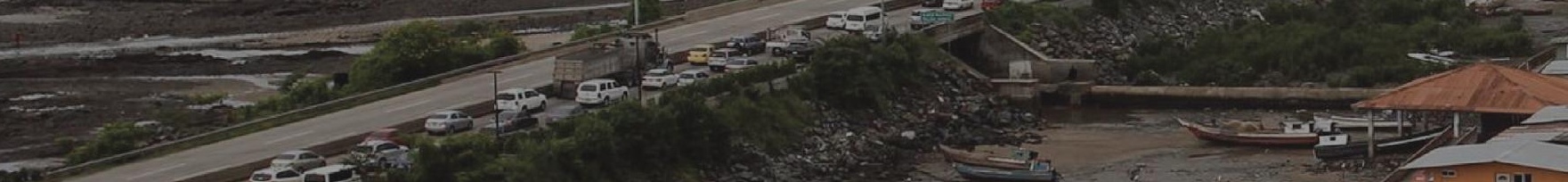
inse- $n=$ Riscos I I I

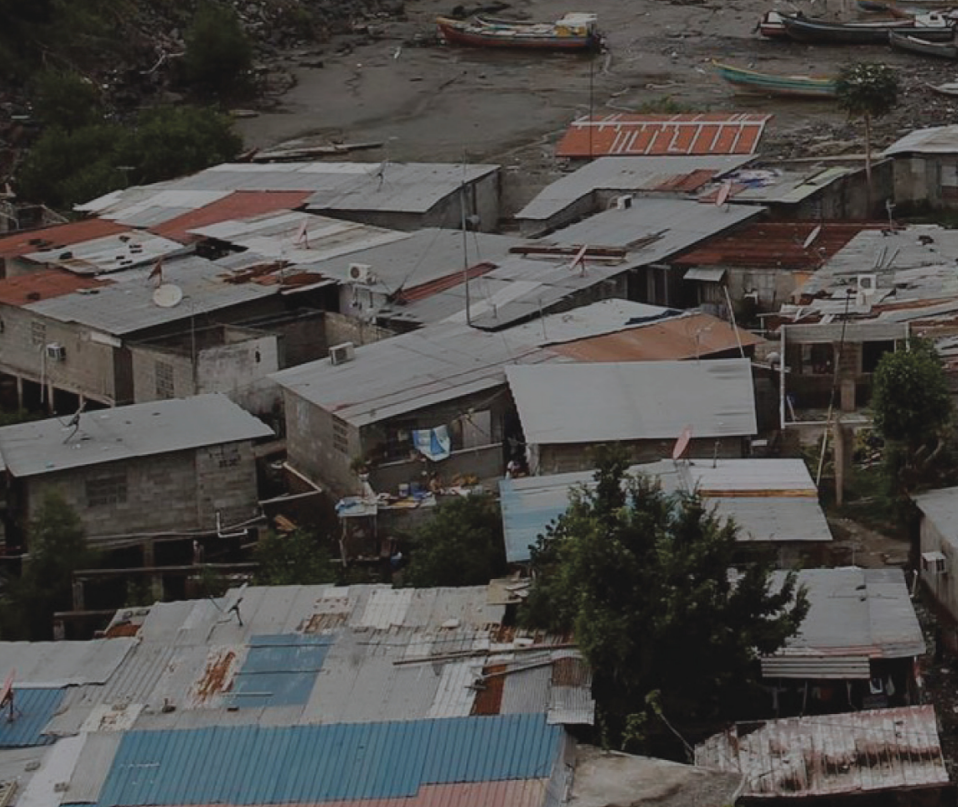

